\section{Rare but lethal disease of childhood: metastatic, mus- cle invasive bladder cancer}

\author{
Serdar Aykan, ${ }^{1}$ Emrah Yuruk, ${ }^{1}$ \\ Murat Tuken, ${ }^{1}$ Mustafa Zafer Temiz,2 \\ Sule Ozsoy 3
}

1Department of Urology, Bagcilar Training and Research Hospital, Istanbul; 2Department of Urology, Bitlis State Hospital; 3Department of Pathology, Bagcilar Training and Research Hospital, Istanbul, Turkey

\section{Abstract}

Bladder cancer is the most common malignancy of urinary tract and the seventh most common cancer in men with the peak incidence in the sixth decade of life. Our knowledge about bladder tumors in pediatric age group mainly relies on case series. The reported cases are mostly low grade and non-muscle invasive. We herein present a case of a 17year-old male with metastatic high-grade muscle-invasive bladder cancer who was presented with macroscopic hematuria and flank pain.

\section{Introduction}

Bladder cancer (BCa) is the most common malignancy of the urinary tract and the seventh most common malignancy of men. ${ }^{1}$ Although most of the patients are initially diagnosed as non-muscle invasive bladder cancer (NMIBC), almost 30\% of them are eventually progress to muscle invasive bladder cancer (MIBC). ${ }^{2}$

The peak incidence of $\mathrm{BCa}$ is in the sixth decade of life, ${ }^{2}$ while they are rarely seen in children. Deming was the first to publish a case of $\mathrm{BCa}$ in a 10 years old patient, almost 9 years ago. ${ }^{3}$ The overall incidence of $\mathrm{BCa}$ is 0.1 $0.4 \%$ in patients under age 20.4

When compared to adult patients almost all of the cases are low grade and non-muscle invasive..$^{4,5}$

The patient presented here had a high grade and rapidly progressive disease that eventually resulted in the death of the patient.

\section{Case Report}

A 17 years old male was presented to our out patient clinic with macroscopic hematuria of 3 weeks. The history of the patient was unre- markable except for smoking while physical examination revealed only pale skin suggestive of anemia. Patient has smoking history as 10 cigarettes a day for 4 years $[(10 / 20) \times 3=1.5$ pack-year]. The hemoglobin level was $6.2 \mathrm{~g} / \mathrm{dL}$. The urinary ultrasound demonstrated a $10-\mathrm{cm}$ mass. The contrast-enhanced thoracic-abdominal computerized tomography (CT) was consistent with an intravesical mass with $8 \mathrm{~cm}$ diameter and suspicious metastatic lesions in the posterior segment of upper pole (14 mm) and medial part of lower pole $(10 \mathrm{~mm})$ of right lung (Figure 1). Although it is not a standard diagnostic tool for $\mathrm{BCa}$, positron-emission tomography (PET) with mCi F-18 fluorodeoxiglucose (FDG) performed for suspicious lung lesions and it revealed the findings of CT scan as lung metastasis with additional hypermetabolic metastatic iliac lymph nodes.

The bimanual examination was compatible with frozen-pelvis. In cystoscopy, the entire bladder wall was occupied with the tumor except for a small area in the dome of the bladder. A subtotal transurethral resection of tumor (TURBT) was performed to confirm the pathological diagnosis, as it was not possible to resect all the tumoral lesions. The pathological specimen was reviewed by two separate adult genitourinary pathologists in two different institutes.

The hematoxylin-eosin sections of the specimen revealed delicate papillas with accompanying fusions. Although the majority of the epithelial cells were arranged regularly, crowded pleomorphic cells in a haphazard alignment with invasion to lamina propria was also noticed. The consensus pathologic diagnosis (Figure 2) of both pathologists blinded to each other was grade 3 transitional cell carcinoma (TCC) based on the 1973 WHO classification (Table 1) and high grade (HG) based on the 2004 WHO classification. However, the staging of the tumor was not accurate because of the lack of muscularis propria in the resected specimen.

A 28-day chemotherapy regimen with gemcitabine $(1500 \mathrm{mg})$ on days 1,8 and 15 and cisplatin $(110 \mathrm{mg})$ on day 1 was initiated because of the lung metastasis seen on PET. The followup CT obtained after the first 2 cycles of chemotherapy revealed progression in the residual bladder tumor and pulmonary lesions. The hemoglobin level of the patient was 4.2 $\mathrm{mg} / \mathrm{dL}$ because of continuous macroscopic hematuria. Following palliative radiotherapy to control hematuria, paclitaxel $\left(80 \mathrm{mg} / \mathrm{k}^{2}\right)$ on day 1,2 and 3 together with adriamycin (50 $\mathrm{mg} / \mathrm{m}^{2}$ ) on day 1 was started for 4 cycles. Selective angio-embolization was required because of persistent hematuria. Bone scintigraphy with $15 \mathrm{mCi} 99 \mathrm{~mm}$ Tc-MDP obtained on July 2014 revealed metastatic lesions at right acetabulum and ischium pubicum. Follow-up CT revealed progression of the pulmonary
Correspondence: Mustafa Zafer Temiz, Department of Urology, Bitlis State Hospital, Besminare Mahallesi 13000, Besminare, Bitlis, Turkey.

Tel.: +90.434.246.8420 - Fax: +90.434.246.8424.

E-mail: dr_mustafazafertemiz@hotmail.com

Key words: Bladder cancer; childhood; metastasis.

Contributions: SA, SO, concept; SA, MT, SO, design; EY, MZ, SO, supervision; EY, MT, MZT, literature search; SA, MZT, MT, manuscript writing; MT, EY, critical review.

Conflict of interest: the authors declare no potential conflict of interest.

Received for publication: 31 March 2015.

Revision received: 7 June 2015.

Accepted for publication: 11 June 2015.

This work is licensed under a Creative Commons Attribution NonCommercial 3.0 License (CC BYNC 3.0).

(C) Copyright S. Aykan et al., 2015

Licensee PAGEPress, Italy

Pediatric Reports 2015; 7:5928

doi:10.4081/pr.2015.5928

lesions and increase in number of involved lymph nodes. Despite aggressive treatment, the patient was lost within the first year of diagnosis.

\section{Discussion}

Urothelial carcinoma is rarely seen during the pediatric age group. ${ }^{6}$ In a comprehensive review of published $\mathrm{BCa}$ series in pediatric age group, Paner et al. showed that muscle invasive and high grade tumors was diagnosed in $3.0 \%$ and $1.7 \%$ of the cases, respectively. ${ }^{7}$ As most of the BCa cases diagnosed during childhood are non-muscle invasive and low-grade, the expected outcome is better than that of the older patients. ${ }^{7}$

There are only two cases reported to have high-grade disease in the literature. The first case was published in 2012 , in a 5 -year old male with gross hematuria. ${ }^{5} \mathrm{He}$ was treated with partial cystectomy followed by 6 -weeks of intravesical bacillus Calmette-Guerin instillations. No recurrence was reported during the 1-year follow-up period. The second case was a 16-year old girl with Hinman syndrome who was diagnosed with invasive transitional cell carcinoma of the bladder. To our knowledge, this is the third case in the literature presenting a high-grade $\mathrm{BCa}$ in a patient younger than 
Table 1. World Health Organization (WHO) grading of bladder tumor in 1973 and 2004.

\begin{tabular}{ll} 
WHO 1973 & WHO 2004 \\
Urothelial papilloma & Urothelial papilloma \\
Grade 1: well differentiated & Papillary urothelial neoplasms of low malignant potential \\
\hline Grade 2: moderately differentiated & Low-grade papillary urothelial carcinoma \\
Grade 3: poorly differentiated & High-grade papillary urothelial carcinoma \\
\hline
\end{tabular}

18 years old. In addition to well known environmental risk factors including smoking, occupational exposure to aniline dyes and phenacetin, some genetic conditions are also associated with increased risk of bladder cancer. ${ }^{8}$ Although multiple-case families with $\mathrm{BCa}$ suggested the presence of a genetic predisposition, it is not clear whether these cases were resulted from a genetic abnormality or common environmental exposure to known carcinogens. ${ }^{9}$ In the present case, the patient was smoking for 3 years, but did not report any $\mathrm{BCa}$ in the family history. Although absence of muscularis propria in the initial resection specimen is an indication for second TURBT, 10 it was not performed, as the further treatment would not change because of the distant organ metastases. Approximately $30 \%$ of the patients with $\mathrm{BCa}$ have muscle invasive while 10 to $15 \%$ of patients are already metastatic at diagnosis. 11 The median survival of patients with metastatic disease rarely exceeded 6 months before the development of modern platinum-based chemotherapy regimens. ${ }^{12}$ Outcome of chemotherapy depends on performance status of the patient and presence or absence of visceral organ metastases. ${ }^{13}$ Cisplatin containing combination therapy is recommended as the first line treatment in metastatic patients with up to $49 \%$ response rates and prolonged survival up to 14.8 months. ${ }^{14}$ However, all these data are collected from adult series and limited evidence exists in the literature for treatment of metastatic disease in children. ${ }^{15}$ Because of progression under gemcitabine/cisplatin chemotherapy, paclitaxel/adriamycin treatment was initiated in this case. Moreover, radiotherapy and selective embolization was performed to control macroscopic hematuria but these palliative interventions yielded only transient response. The disease control was not established despite second-line chemotherapy and the patient died soon after diagnosis of bone metastases.

\section{Conclusions}

We herein reported a rapidly progressive case of high grade $\mathrm{BCa}$ in a young boy. Although uncommon, BCa should always be kept in mind when evaluating macroscopic hematuria in children. In patients with high-
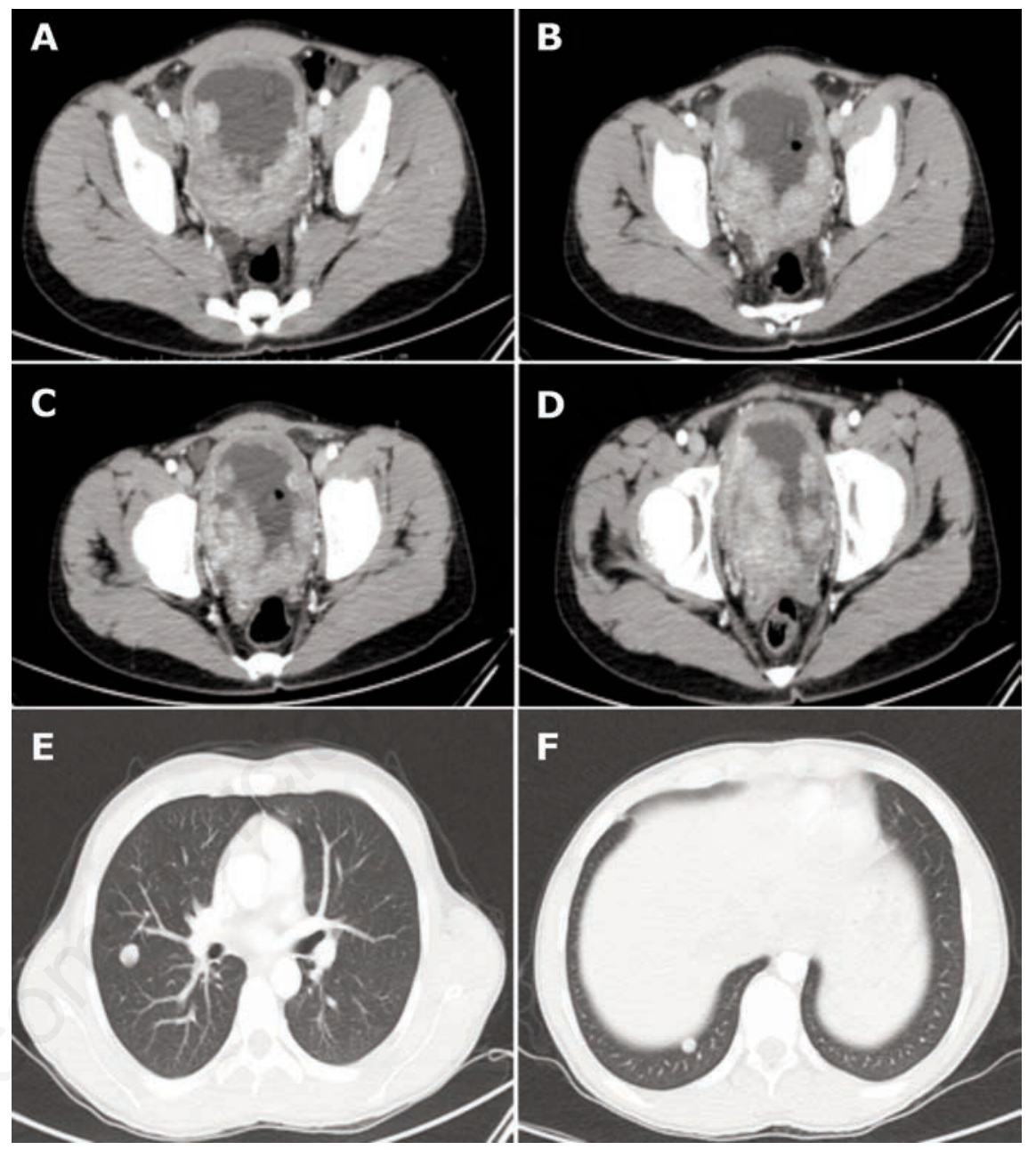

Figure 1. A-D) Preoperative contrast enhanced computerized tomography of the patient. Most of the lateral and posterior walls are occupied with the tumor. E,F) Computerized tomography of the thorax revealed multiple nodular metastatic lesions.

grade disease, aggressive resection should be performed and chemotherapy should be considered in the attempt to control the disease and prevent progression and metastases.

\section{References}

1. Siegel R, Naishadham D, Jemal A. Cancer statistics, 2012. CA Cancer J Clin 2012;62:10-29.

2. Zuiverloon TC, Abas CS, Van Der Keur KA, et al. In-depth investigation of the molecu- lar pathogenesis of bladder cancer in a unique 26-year old patient with extensive multifocal disease: a case report. BMC Urol 2010;10:5.

3. Lerena J, Krauel L, Garcia-Aparicio L, et al. Transitional cell carcinoma of the bladder in children and adolescents: six-case series and review of the literature. $\mathrm{J}$ Pediatr Urol 2010;6:481-5.

4. Berrettini A, Castagnetti M, Salerno A, et al. Bladder urothelial neoplasms in pediatric age: experience at three tertiary centers. J Pediatr Urol 2015;11:e1-5.

5. Garrett SK, Eugene A. Minevich I, et al. 


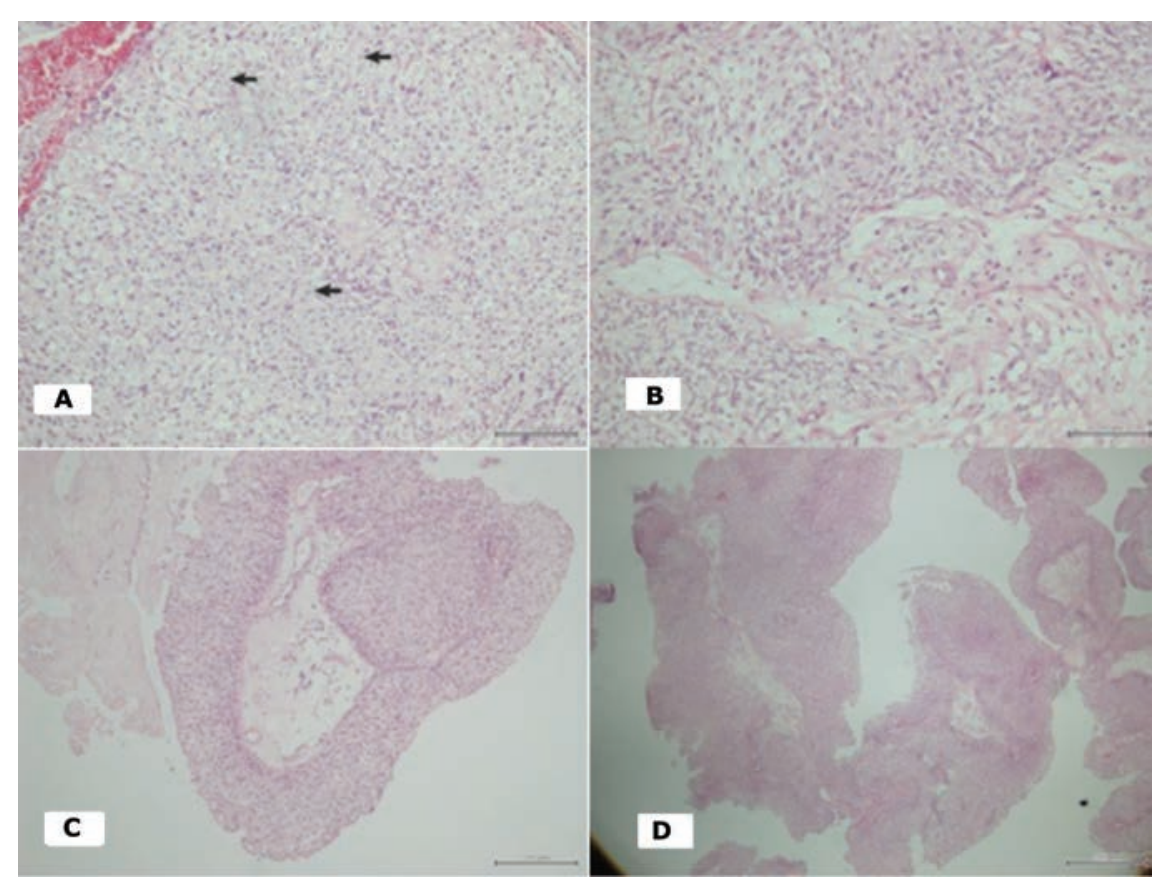

Figure 2. A) High grade urothelial carcinoma with haphazardly arranged cells with significant nuclear pleomorohism and atypical mitosis, Hematoxylin and Eosin 200x. B) High grade urothelial carcinoma with stromal invasion Hematoxylin and Eosin 400x. C) High grade urothelial carcinoma, Hematoxylin and Eosin 100x. D) High grade urothelial carcinoma with papillary fronds, Hematoxylin and Eosin $40 \times$.

High-grade transitional cell carcinoma of the pediatric bladder $\mathrm{J}$ Pediatr Urol 2011;8:e36-8.

6. Fine SW, Humphrey PA, Dehner LP, et al. Urothelial neoplasms in patients 20 years or younger: a clinicopathological analysis using the world health organization 2004 bladder consensus classification. J Urol 2005; $174: 1976-80$.

7. Anas IG, Charles TD, Travis W. Groth advanced transitional cell carcinoma of the bladder in a 16-year-old girl with Hinman syndrome. Urology 2012;80:11413.
8. Giedl J, Wild PJ, Stoehr R, et al. Urothelial neoplasms in individuals younger than 20 years show very few genetic alterations and have a favourable clinical outcome. Verh Dtsch Ges Pathol 2006;90:253-63.

9. Mueller CM, Caporaso N, Greene MH. Familial and genetic risk of transitional cell carcinoma of the urinary tract. Urol Oncol 2008;26:451-64.

10. Babjuk M, Oosterlinck W, Sylvester R, et al. EAU guidelines on non-muscle-invasive urothelial carcinoma of the bladder, the 2011 update. Eur Urol 2011;59:997-1008.

11. Roupret M, Zigeuner R, Palou J, et al. European Guidelines for the diagnosis and management of upper urinary tract urothelial cell carcinomas: 2011 update. Eur Urol 2011;59:584-94.

12. Stemberg CN, Pansadoro V, Calabro F, et al. Can patient selection for bladder preservation be based on response to chemotherapy? Cancer 2003;97:1644-52.

13. Bajorin DF, Dodd PM, Mazumdar M, et al. Long term survival in metastatic transitional-cell carcinoma and prognostic factors predicting outcome of therapy. J Clin Oncol 1999;17:3173-81.

14. Von Der Maase H, Sengelov L, Roberts JT, et al. Long term survival results of a randomized trial comparing gemcitabine plus cisplatin, with methotrexate, vinblastine, doxorubicine, plus cisplatin in patients with bladder cancer. J Clin Oncol 2005;23: 4602-8.

15. Galsky MD, Krege S, Lin CC, et al. Cisplatin-based combination chemotherapy in septuagenarians with metastatic urothelial cancer. Urol Oncol 2014;32:e1521. 